\title{
OS DIREITOS SOCIAIS COMO CAUSAS CÍVICAS*
}

\section{Marco Aurélio Nogueira**}

RESUMO: O tema específico desta mesa-redonda - "Políticas contemporâneas: fim do direito à saúde?" - apresenta uma questão de grande magnitude, que afeta a sociabilidade contemporânea como um todo: dadas as ameaças e dificuldades que hoje se antepõem aos direitos sociais, estariam eles à beira do precipício, prestes a desaparecer? A contribuição para esta discussão deve estabelecer uma perspectiva mais geral, fazendo uma tentativa de colocar os direitos como problema inerente a nossa sociedade, e à forma como fazemos política e organizamos a política. $\mathrm{O}$ autor mostra algumas teses ou hipóteses de trabalho oriundas das suas pesquisas e conclui sua palestra nos conclamando a pensar saídas sem com isso querer sugerir nenhuma pauta de soluções mas fixar algumas idéias preliminares que não garantem o encontro de saídas, mas sem elas as saídas não aparecerão.

PALAVRAS-CHAVE: política, direitos, direitos sociais

\footnotetext{
* Apresentado na Mesa Redonda Políticas Contemporâneas: fim do direito à saúde?, em 01/10/01, VII Congresso Paulista de Saúde Pública.

** Professor Adjunto de Teoria Política da Faculdade de Ciências e Letras, Campus de Araraquara, da Universidade Estadual Paulista - UNESP - Araraquara.
} 


\section{INTRODUÇÃO}

É com grande prazer que participo deste Congresso, cuja relevância já é conhecida de todos. No momento atual, parece-me da maior importância manter vivo o tema geral que estrutura o presente Congresso - Saúde e Democracia - , caro às melhores tradições da Saúde Pública no Brasil. Do mesmo modo, o tema específico desta mesa-redonda - "Políticas contemporâneas: fim do direito à saúde?" - põe-nos diante de uma questão de grande magnitude, que afeta a sociabilidade contemporânea como um todo: dadas as ameaças e dificuldades que hoje se antepõem aos direitos sociais, estariam eles à beira do precipício, prestes a desaparecer?

Não sou um profissional da área da Saúde. Tenho o privilégio de manter uma relação de profunda intimidade com a Saúde Pública - um relacionamento marcado por relações afetivas muito fortes e por experiências coletivas que valorizo extremamente - , mas não trabalho nem nunca trabalhei diretamente com a Saúde Pública. Por isto, como cientista político, creio poder contribuir para esta discussão procurando estabelecer uma perspectiva mais geral, fazendo uma tentativa de colocar os direitos como problema inerente a nossa sociedade, ao nosso modo de viver e à forma como fazemos política e organizamos a política.

Gostaria de fixar, inicialmente, algumas teses ou hipóteses de trabalho. Antes de tudo, porém, esclareço que boa parte do que vou falar aqui integra um livro que publiquei pouco tempo faz, chamado Em Defesa da Política (São Paulo, Editora SENAC, 2001), no qual há um capítulo intitulado "A cidadania sangrada", que usarei como base para minha argumentação.

\section{PARA PENSAR OS DIREITOS}

Primeira tese. Os direitos humanos, e particularmente os direitos sociais (e, entre eles, o direito à saúde), são um parâmetro fundamental da vida civilizada e refletem conquistas importantes do movimento democrático e das lutas sociais dos séculos XIX e XX. São uma prova cabal de que a humanidade tem sabido construir, ao lado da exacerbação do mercado, da competição, da violência e da exploração, formas mais dignas de convivência. Os direitos 
sociais, porém, não são uma dádiva, nem uma concessão. Foram "arrancados" por lutas e operações políticas complexas. Além disso, também têm funcionado como um importante fator de reprodução social e reposição da força de trabalho: não são uma doação dos poderosos, mas um recurso com o qual os poderosos se adaptam às novas circunstâncias histórico-sociais, dobrando-se com isso, contraditoriamente, às exigências e pressões em favor de mais vida civilizada. São, em suma, um fator que viabiliza o sistema e ao mesmo tempo um fator que ajuda a que avance a oposição ao sistema. Justamente por isso, os direitos sociais são indispensáveis para que se possa pensar numa forma democrática e justa de vida; no mínimo por isto, merecem ser plenamente valorizados e defendidos.

Segunda tese. Nas últimas décadas, a cidadania dilatou-se de forma inédita e inusitada. O campo dos direitos humanos está hoje definido pela reiteração de antigas conquistas (direitos civis e políticos), pela oscilação dos direitos sociais e pela afirmação incessante de "novos direitos", que recobrem territórios tão vastos quanto o meio ambiente, a sexualidade e a bioética. A vida moderna ficou inseparável de um progressivo mas tenso e irregular reconhecimento jurídico dos direitos humanos. Ao mesmo tempo, a luta por direitos está longe de se ter esgotado ou de ter encontrado um ritmo regular. Paralelamente à reiteração jurídico-formal dos direitos, continuam a se multiplicar as situações de desrespeito, preconceito, exclusão e indiferença, assim como a se prolongar as situações de marginalidade, "desproteção" e arbítrio.

Terceira tese: o quadro dos direitos humanos encontra-se complicado e ameaçado pelos impactos e desdobramentos da globalização, que retira soberania dos Estados nacionais e, com isso, reduz sua capacidade de regular, controlar e proteger, e os impede de continuar operando como fonte de garantia de expectativas normativas. Os direitos humanos em geral e particularmente os direitos sociais ficam, deste modo, sem o devido anteparo estatal, correndo o risco de se perderem ou de simplesmente de não serem efetivados. Na marcha rumo à "sociedade global", emergem novos espaços de produção de direitos que, no entanto, não gozam de garantias ou proteções consistentes, ficando na dependência da vontade política dos governantes, da dura luta dos interessados ou da ativação política da sociedade civil.

Quarta tese. Apesar de vivermos numa "era de direitos", repleta de conquistas e avanços, os direitos sociais parecem hoje viver muito mais como direitos proclamados, "direitos em sentido fraco", ou expectativas de direitos, como diria Norberto Bobbio, que como direitos efetivamente usufruídos, ou seja, "direitos em sentido forte". Há, no campo 
dos direitos sociais, um maior grau de defasagem entre a norma jurídica e a sua efetiva aplicação. Trata-se de uma defasagem comum a todas as áreas, mas que, na área social, parece ser maior, basicamente porque os direitos sociais dependem muito, para ser efetivamente usufruídos, de decisões políticas cotidianas, tomadas praticamente no dia-adia. Os direitos sociais trazem consigo, como sabemos, a necessidade de alocações expressivas de recursos: financeiros, humanos, técnico-científicos, organizacionais, políticos, seja para financiar os direitos, seja para viabilizá-los no plano organizacional. Como são recursos de natureza ampla, quase sempre mexem com interesses estabelecidos, e por isso acabam ficando na dependência de acertos, acordos, pactos societais, decisões de natureza governamental e política, que muitas vezes compromètem a efetiva aplicação, implementação e proteção desses direitos.

Quinta tese: os direitos sociais são direitos de um tipo especial, já que não implicam a possibilidade da criminalização. Diferentemente dos demais tipos de direitos, que trazem consigo a possibilidade de penalizar aqueles que os infringem, no caso dos direitos sociais essa possibilidade, ou não existe, ou está radicalmente enfraquecida, inviabilizada pela própria natureza desses direitos. O governante que não cumpre o que estabelece a norma constitucional no plano dos direitos sociais pode, quando muito, sofrer sanções morais e desgaste político. Somente será criminalizado se o não-cumprimento vier acompanhado de atos abertos de corrupção: a incompetência ou a opção por uma política social inconsistente, equivocada, prejudicial à população, não são "crimes". Vale a pena, portanto, pensar na provocativa pergunta feita por Bobbio: será que ainda podemos chamar de direito "um direito cujo reconhecimento e cuja efetiva proteção podem ser adiados sine die, além de confiados à vontade de sujeitos cuja obrigação de executar o 'programa' é apenas uma obrigação moral ou, no máximo, política"? (Bobbio, $A$ era dos direitos. Rio de Janeiro: Editora Campus, 1992, p. 77). Podemos, é claro, continuar chamando de direitos estas exigências, que são sobretudo expectativas de direitos, mas só teremos a ganhar se soubermos evitar a confusão entre uma exigência de proteção futura de um certo bem (a saúde, por exemplo), que posso proclamar e exigir com certa facilidade, e a proteção efetiva desse bem, algo que muitas vezes só posso conquistar mediante recurso a uma corte de justiça. No campo dos direitos sociais, não há tribunais capazes de reparar erros gerenciais, má alocação de verbas ou opções políticas equivocadas, nem muito menos de punir os culpados.

\section{PROCURANDO AS DETERMINAÇÕES}

Se sairmos desse terreno mais abstrato e olharmos para o terreno concreto, podemos 
ver que toda a problematicidade inerente aos direitos sociais está no Brasil bastante amplificada. Não somos protagonistas de uma experiência histórica rica na elaboração de pactos sociais consistentes. Quero dizer com isto que têm sido precários, entre nós, os arranjos políticos dedicados a estruturar e a viabilizar, por exemplo, transferências de renda e escolhas públicas voltadas para a valorização e a proteção efetiva dos direitos sociais. Faltam-nos lealdades políticas e lealdades sociais para que se tomem decisões firmes em favor de direitos. Em decorrência, os direitos sociais não têm sido muito respeitados e nem têm fluído em condições razoáveis. Hoje, além do mais, no quadro de uma globalização hegemonizada pelo mercado, a situação fica dramaticamente agravada.

Como sustentar, digamos assim, as teses que apresentei acima? Quais os fatores que determinam o atual estado de dificuldades e restrições que afetam os direitos sociais? Gostaria de apresentar alguns pontos que, na minha avaliação, ajudam a explicar estas restrições e dificuldades e, ao mesmo tempo, a avaliar os caminhos que temos de trilhar para fazer com que esses direitos especiais, que são os direitos sociais, ganhem consistência, estabilidade, proteção e efetiva aplicação.

Começaria dizendo que conhecemos hoje uma situação de crise do Estado, e dentro da crise do Estado uma situação de crise do Estado nacional. Podemos aliviar um pouco a carga dramática dessa idéia de crise - afastá-la claramente, por exemplo, de qualquer visão apocalíptica, associada a morte, a fim, a colapso definitivo - , mas seguramente não temos como negar que existe hoje um profundo mal-estar nessa área, um desarranjo, uma falta de coordenação, uma falta de estruturação. Com isso, estamos perdendo o terreno histórico-social concreto em que se vincularam até hoje e em que foram praticados os direitos, e os direitos sociais em primeira instância. Tais direitos vivem hoje ao sabor de turbulências internacionais, escassez de recursos, planos de estabilidade recessivos, ajustes, pressões e constrangimentos de diferentes tipos. Justamente por isso, flutuam sem encontrar a devida proteção jurídica e política.

Associado a este quadro, há um outro processo: estamos vivendo uma fase em que predomina no mundo uma mentalidade de mercado. Gostemos ou não gostemos disto, estamos obrigados a reconhecer que este é um fato da realidade. A visão de que o mercado funciona como parâmetro e como recurso para obter todos os bens parece-me hoje dominante, dominante não necessariamente no coração do povo mas seguramente na cabeça dos dirigentes políticos, na cabeça dos gestores, dos gerentes, dos empresários, de muitos dirigentes associativos, de muitos formadores de opinião. Sendo verdadeiro isso, 
tudo tende a ser reduzido a uma relação de compra e venda, tudo tende a virar mercadoria, incluindo os direitos, a justiça, a igualdade e assim por diante. Hoje temos uma situação tendencialmente disposta no sentido da idéia de que os direitos sociais também podem ser "comprados": os que podem pagar por eles são lançados para fora do campo público e os direitos sociais propriamente ditos (direitos publicamente garantidos, universais, cobertos pelo imposto recolhido pela sociedade) são, quando muito, previstos exclusivamente para os mais pobres. Trata-se de uma tendência que até pode repercutir positivamente em termos de finanças públicas, mas que seguramente enfraquece o campo dos direitos sociais e tira legitimidade deles.

Os direitos estão complicados, também, em terceiro lugar, porque temos hoje no mundo, e portanto também no Brasil, uma espécie de crise da idéia de cidadão. A idéia de cidadão é uma idéia sofisticada, complicada, e hoje me parece que ela está em crise sobretudo porque tende a se afirmar quase que exclusivamente no plano dos direitos, deixando para trás o plano das obrigações. È uma conseqüência do clima geral, de pouca perspectiva coletiva e muito individualismo. Junto com a crise da idéia de cidadão há uma crise da idéia de República, ou seja, o cidadão republicano está hoje gravemente reduzido ou à condição de consumidor ou à condição de eleitor, de alguém que é chamado a referendar decisões que são tomadas em âmbitos aos quais ele não tem acesso. Os cidadãos reclamam, protestam, fazem plebiscitos, votam regularmente de dois em dois anos ou de quatro em quatro, mas não conseguem entrar no ventre em que são geradas as decisões.

Além do mais, somos protagonistas de uma época que assiste a uma espécie de colisão entre o social e o institucional. Trata-se de uma situação que se manifesta com força no Brasil. Estamos vivendo num momento da nossa sociedade em que o plano social está muito excitado, muito exacerbado, ficou muito complexo; é diferenciado, diversificado, conhece uma enorme dispersão em termos de interesses. Há problemas sociais gravíssimos, como todos sabemos, e as instituições não dão conta disso, não conseguem assimilar e muito menos direcionar, dirigir o social. Essa defasagem entre o mundo social, o mundo dos interesses, o mundo das pessoas, e o mundo das instituições é uma defasagem grave que não só torna extremamente difíceis a reprodução e a renovação dos pactos fundamentais, como torna também extremamente árdua a organização dos instrumentos com os quais podem ser implementadas políticas sociais, e sobretudo políticas sociais mais agressivas.

Em quinto lugar, precisamos reconhecer também que, nesse contexto, afirma-se uma idéia perversa de reforma - de reforma da administração pública e de reforma do 
Estado, sobretudo - , ou seja, uma visão que reduz a reforma ao plano técnico-administrativo e ao plano fiscal-financeiro. Com isto, o reformismo com que atravessamos a última década do século XX acabou, de um lado, por despolitizar radicalmente todo o debate a respeito de seu sentido e de seu programa: tornou-se um reformismo incapaz de se completar e de se desdobrar em resultados socialmente expressivos, que não tiveram como encontrar espaço na dinâmica reformadora. De outro lado, tal reformismo ajudou a fazer com que as instituições passassem a sangrar e a se desmobilizar: quebrou com as identidades delas, liquidou seus recursos humanos, sucateou seu principal patrimônio. Tal idéia de reforma, que está bastante concentrada no barateamento dos serviços e no enxugamento da burocracia, alimenta operações gerenciais que levam as organizações à falência. As organizações públicas, maltratadas dos mais diferentes modos, ainda por cima são consideradas como despreparadas para enfrentar o ambiente competitivo em que se vive, devendo ceder espaço para organizações mais "modernas", quase sempre vistas como market oriented.

Processa-se, enfim, vinculado a esse quadro, uma espécie de sofrimento organizacional generalizado: as organizações, todas elas, no mundo todo, estão sofrendo, a vida organizada está sofrendo. Para fazer uma brincadeira bem adequada a um ambiente de profissionais da saúde, é como se o mundo estivesse doente, e se o mundo está doente as organizações adoecem também, e sem organizações a vida fica muito complicada, principalmente no campo dos direitos e dos direitos sociais em particular. Como as organizações estão sofrendo, elas tendem a criar condições para o aparecimento, no interior delas, de uma elite de gestores sem audácia e sem criatividade, gestores opacos, desvinculados de interesses ou compromissos organizacionais, carentes de responsabilidades públicas, que atuam com os olhos naquilo que é considerado o up to date da ciência administrativa, com os olhos no caixa, com os olhos em estratégias gerenciais de último tipo, e acabam, nesta operação, por minar as resistências organizacionais. Se passarmos uma vista panorâmica sobre as organizações públicas, do campo técnicoburocrático e científico do Estado de São Paulo, veremos uma situação aterradora: as organizações são pressionadas a partir de fora (via cortes orçamentários ou imposições políticas, por exemplo) e não estão conseguindo contar com boas e qualificadas respostas a partir de dentro delas. As universidades estaduais, por exemplo, graças à autonomia financeira e à valorização do mérito acadêmico, sofrem por falta de políticas educacionais consistentes e pelos incentivos que são dados ao ensino particular, mas também são condicionadas por seu próprio ambiente interno, que também passou a registrar uma forte inflexão no sentido da competitividade e do produtivismo. Já as instituições de apoio técnico ou administrativo, decisivas para o sucesso de tantas operações governamentais, são 
atingidas não só pela asfixia orçamentária empreendida pelos governos, como também por verdadeiras campanhas "oficiosas" de desqualificação, ficando à mercê de gestores mais afinados com as orientações dominantes, que buscam tomar conta das instituições, demitem profissionais experientes em nome do enxugamento da folha, interferem nos equilíbrios organizacionais, estabelecendo planos estratégicos que convertem instituições técnicocientíficas em instituições de prestação de serviços, meras extensões do aparato administrativo dos governos. Algumas instituições ainda conseguem resistir, mas muitas outras vão perdendo forças, quadros e personalidade. Trata-se, no fundo, da desmontagem de toda uma rede institucional que poderia desempenhar um papel fundamental no campo técnico e político, e com isso ajudar a que certas políticas ganhassem maior consistência, maiores chances de implementação, maior controle técnico, e assim por diante.

\section{PARA O ENCONTRO DE SAÍDAS}

Sendo esse o quadro, em que saídas podemos pensar? Não há como sugerir nenhuma pauta de soluções, mas gostaria de fixar, rapidamente, a título de conclusão, algumas idéias preliminares. Elas não garantem o encontro de saídas, mas sem elas as saídas não aparecerão.

O primeiro ponto é que teremos de descobrir pela política, pelo social, pelo intelectual, por fóruns como esse, uma forma de colocar em curso um novo movimento de valorização da norma, um novo movimento de valorização do Estado, não do Estado reduzido a aparato de intervenção, porque deste, num certo sentido, nós até temos bastante, mas do Estado como expressão jurídica de pactos coletivos consistentes, com os quais seja possível no mínimo domesticar o mercado e frear a predação do patrimônio público. Sem essa valorização da idéia da norma, da idéia do pacto, da idéia do Estado, não teremos como estabelecer um sentido comum, republicano, democrático, para a vida social.

O segundo ponto é uma espécie de princípio: se é verdade que há hoje uma crise no campo dos direitos sociais, que estão sendo questionados pelas mudanças que a inovação tecnológica, a globalização da economia e da comunicação, os avanços científicos e a reorganização das relações internacionais estão provocando na estrutura produtiva, no Estado, na vida em geral, se é verdade que há uma crise neste campo, também é verdade que a questão dos direitos e da luta por direitos é ineliminável e se reproduz de modo 
inevitável. Ela não consegue ser silenciada, nem desativada, nem represada. Em boa medida, a questão dos direitos espelha o mundo em que vivemos, com suas injustiças, suas desigualdades, seus dilemas e suas contradições. A luta por direitos, por isso, quando devidamente politizada, nos coloca de novo, o tempo todo, no olho do furacão, ou seja, no terreno dos conflitos, das lutas sociais, e acaba por nos animar a brigar por uma ordem social justa, sem miséria, sem exclusões, sem desigualdades.

O terceiro ponto é que teremos de afastar os direitos do campo de que eles estão se aproximando perigosamente hoje. $O$ que quero dizer com isso é um outro princípio: os direitos, e sobretudo os direitos sociais, não são um item do orçamento público, não podem ser reduzidos ao financeiro, às condições financeiras das sociedades e muito menos às opções de política financeira feitas pelos governos das sociedades.

Não sou ingênuo de achar que o financeiro não pesa. Ele pesa e pesa muito, mas se nós não salvarmos os direitos da lógica financeira, não vejo como eles poderão ser implementados e protegidos. O determinismo economicista, a mentalidade contábil e a arrogância fiscalista do nosso tempo, dependentes que são do fundamentalismo de mercado hoje prevalecente, mostram sua pior face ao conceber os direitos como itens do orçamento. Os direitos não podem assentar no mercado: eles não são personagens do mercado, mas do Estado, e somente no Estado podem encontrar proteção e viabilidade. Estão inseridos, portanto, no coração da política, da política entendida como atividade específica dos humanos, como sistema de normas, regras, instituições, valores, lutas, a partir do qual a convivência se torna possível, um campo no qual a guerra pode ser evitada e a desgraça social pode ser eliminada.

O último ponto é que teremos de aprender a lutar por direitos num plano político superior. A luta por direitos não tem qualquer viabilidade se dissociada da luta política democrática. A "estratégia dos direitos", tão valorizada pela movimentação social, não tem como se completar fora da política: hipostasiada, tal estratégia produz apenas expectativas mal-dimensionadas e frustrações. Do mesmo modo, os direitos sociais não podem ser proclamados e defendidos em termos corporativos, como se fossem "propriedade" de um grupo ou de uma profissão, de um partido ou de outro. Eles só têm chance se forem defendidos como causas cívicas coletivas, causas políticas, justamente porque anunciam formas novas e melhores de convivência e responsabilidade recíproca. Em alguma medida, portanto, a dinâmica dos direitos tende a ser subversiva, a se indispor contra a ordem, pois aponta para novos padrões de convivência e estruturação social. 
Estou certo de que é justamente por isso que os direitos costumam ser banalizados, perseguidos, desvalorizados, por todos aqueles que se imaginam pilotando a reprodução ampliada da ordem.

\title{
THE SOCIAL RIGHTS AS CIVIC CAUSES
}

\begin{abstract}
ABSTRAT: The specific topic of this panel "Contemporary Policies: is it the end of right to health?" poses a broad question that affects contemporary sociability as a whole: given the threats and difficulties that counter social rights, would these rights be on the edge of a precipice and likely to disappear? The contribution to this discussion should establish a more general perspective, trying to consider rights as a problem inherent to our society and related to how we play and organize politics. The author demonstrates some theses or hypotheses related to his research and concludes his lecture calling us to think about ways out. However he does not suggest any agenda of solutions, he rather sets some preliminary ideas that do not guarantee finding ways out. But with no ideas the ways out will not appear.
\end{abstract}

KEYWORDS: politics; rights; social rights 